\title{
Participant retention in follow-up studies of prematurely born children
}

Victoria MacBean', Simon B. Drysdale ${ }^{2}$, Sanja Zivanovic ${ }^{3}$, Janet L. Peacock ${ }^{4,5}$ and Anne Greenough ${ }^{5,6,7^{*}}$ (D)

\begin{abstract}
Background: Follow-up studies of infants born prematurely are essential to understand the long-term consequences of preterm birth and the efficacy of interventions delivered in the neonatal period. Retention of participants for followup studies, however, is challenging, with attrition rates of up to $70 \%$. Our aim was to examine retention rates in two follow-up studies of prematurely born children and identify participant or study characteristics that were associated with higher attrition, and to discuss retention strategies with regard to the literature.

Methods: Data from children recruited at birth to one of two studies of prematurely born infants were assessed. The two studies were the United Kingdom Oscillation Study (UKOS, a randomised study comparing two modes of neonatal ventilation in infants born less than 29 weeks of gestational age (GA)), and an observational study examining the impact of viral lower respiratory tract infections in infancy in those born less than 36 weeks of GA (virus study). The UKOS participants, but not those in the virus study, had regularly been contacted throughout the follow-up period. UKOS subjects were followed up at 11 to 14 years of age and subjects in the virus study at 5-7 years of age. At follow up in both studies, pulmonary function and respiratory morbidity were assessed. Retention rates to follow-up in the two studies and baseline characteristics of those who were and were not retained were assessed.

Results: Retention was significantly higher in UKOS than the virus study (61\% versus $35 \%, p<0.0001)$. Subjects lost to UKOS follow up had greater deprivation scores $(p<0.001)$, a greater likelihood of intrauterine tobacco exposure $(p=0.001)$ and were more likely to be of non-white ethnicity $(p<0.001)$. In the virus study, those lost to follow-up had higher birth weights $(p=0.036)$ and were less likely to be oxygen dependent at hospital discharge $(p=0.003)$ or be part of a multiple birth $(p=0.048)$.

Conclusions: Higher retention was demonstrated when there was regular contact in the follow-up period. Both social factors and initial illness severity affected the retention into follow-up studies of prematurely born infants, though these factors were not consistent across the two studies.
\end{abstract}

Keywords: Recruitment, Follow-up study, Prematurity

\section{Background}

Follow-up studies of infants born prematurely are essential to understand the long-term consequences of preterm birth and the efficacy of interventions delivered in the neonatal period. There are a number of studies whose short-term results have been at variance with important outcomes at follow up [1-3]. Retention of

\footnotetext{
* Correspondence: anne.greenough@kcl.ac.uk

${ }^{5} \mathrm{NIHR}$ Biomedical Research Centre at Guy's \& St Thomas' NHS Foundation

Trust and King's College London, London, UK

${ }^{6}$ Department of Women and Children's Health, School of Life Course

Sciences, Faculty of Life Sciences \& Medicine, King's College London,

London, UK

Full list of author information is available at the end of the article
}

participants for follow-up studies, however, is challenging, with attrition rates of up to $70 \%$ [4]. Participant attrition results in loss of statistical power and may introduce bias into study results. Strategies, therefore, are required to mitigate attrition, in order that the value of prospectively recruited cohorts is not lost. We have conducted two studies involving long-term follow-up of cohorts of children born prematurely. Our aims were to compare retention at follow-up of the two studies, highlight methodological differences between the studies' follow-up design that may have influenced retention, identify any groups at particular risk of attrition, and discuss retention strategies with regard to the literature.

(c) The Author(s). 2019 Open Access This article is distributed under the terms of the Creative Commons Attribution 4.0 International License (http://creativecommons.org/licenses/by/4.0/), which permits unrestricted use, distribution, and 


\section{Methods}

Analysis was undertaken of the results of the followup study of the United Kingdom Oscillation study (UKOS) and a follow-up study assessing the outcomes of viral infections in infancy of prematurely born infants (virus study). The follow-up studies were approved by the South West London National Research Ethics Service Committee and the National Research Ethics Service Committee West Midlands - Coventry \& Warwickshire respectively. Informed, written parental consent was given for all the children to take part in the follow-up studies.

\section{United Kingdom Oscillation Study (UKOS)}

UKOS [5] was a multicentre, randomised trial comparing the efficacy of high frequency oscillatory ventilation to conventional mechanical ventilation initiated within an hour after birth in infants born prior to 29 weeks of gestational age. The UKOS cohort was recruited from 22 centres in the United Kingdom, as well as one centre in each of Ireland, Singapore and Australia. Follow-up, however, was only attempted in children from the UK and Ireland. A subgroup had lung function assessments at 1 year [6] and all were seen by their local paediatrician at 2 years who documented the children's healthcare utilisation and respiratory symptoms [7]. All UKOS participants were sent birthday and season greeting cards each year. There was also an online presence in the form of a blog (https://ukos.wordpress.com/), which provided parents and children with regular study updates and information about publications from the study.

UKOS participants were asked to attend for follow up at King's College Hospital NHS Foundation Trust $(\mathrm{KCH})$ at 11 to 14 years when pulmonary function, atopy, environmental tobacco smoke exposure, behavioural outcomes, health-related quality of life and academic achievements were assessed [1].

\section{Virus study}

A single centre, observational study was undertaken at $\mathrm{KCH}$ to examine the impact of viral lower respiratory tract infections (LRTIs) in infancy on respiratory morbidity and pulmonary function. Pulmonary function was measured at 1 year of age [8] and healthcare utilisation was recorded over the first year after hospital discharge and health related costs of care calculated [9]. The cohort was then recalled at 5-7 years of age for pulmonary function and healthcare utilisation assessment [10]. Families did not receive any communication from the research team between completion of the initial follow-up study and the invitation to the school-age follow up.

\section{Analysis}

Baseline characteristics of participants in each study who were and were not successfully followed up were compared in order to identify factors that might influence retention. Infant characteristics were selected for comparison as these are known at the enrolment stage and any differences identified would highlight for future authors groups in whom specific retention strategies would be required. The baseline characteristics available for both cohorts (sex, maternal ethnicity, socioeconomic status (index of multiple deprivation (IMD), birth weight, gestational age, whether the infant was part of a multiple birth, whether surfactant had been given, tobacco exposure in utero, whether postnatal steroids had been administered and whether the infant was oxygen dependent at 28 days and at hospital discharge) of the children who were and were not retained to the follow up stage of the studies were compared using unpaired t-tests and Chi square tests (for normally-distributed data) or the Mann-Whitney test and Fisher's exact test (for non-parametric data). Data analysis was undertaken using SPSS Version 24 (IBM Corp, Chicago, IL).

\section{Results}

At the UKOS 11 to 14-year follow-up, a total of 592 children who had survived to hospital discharge were eligible for participation, of whom 319 (54\%) were studied (Fig. 1). Excluding subjects in whom follow up was not attempted (recruited at an overseas site or died prior to follow-up), the retention rate was $61 \%$. At school-age follow up in the virus study 56 children (35\%) were successfully studied (Fig. 2) [10]. The follow-up rate was significantly lower in the virus study compared to UKOS $(p<0.0001)$ as indicated by Chi-squared analysis.

Baseline characteristics of those subjects who were and were not retained in the UKOS follow up study demonstrated significant differences regarding ethnicity, index of multiple deprivation and maternal smoking in pregnancy (Table 1 ). Non-white ethnicity was more prevalent in those lost to follow-up $(p<0.001)$. Those infants who did not attend follow-up also had significantly higher rates of in utero tobacco exposure $(p=0.001)$ and higher socioeconomic deprivation scores $(p<0.001)$. In the virus study, those not followed up had significantly higher birth weights $(p=0.036)$ and were significantly less likely to be oxygen dependent at discharge $(p=0.003)$ or be a multiple birth $(p=0.048$, Table 2$)$.

Across both studies, there were no differences observed in sex, gestational age, postnatal steroid administration, oxygen requirement at 28 days, or rates of surfactant administration between those infants who were and were not successfully followed up. There were no common characteristics across the two studies in which differences were observed in those who did and did not attend for follow up. 


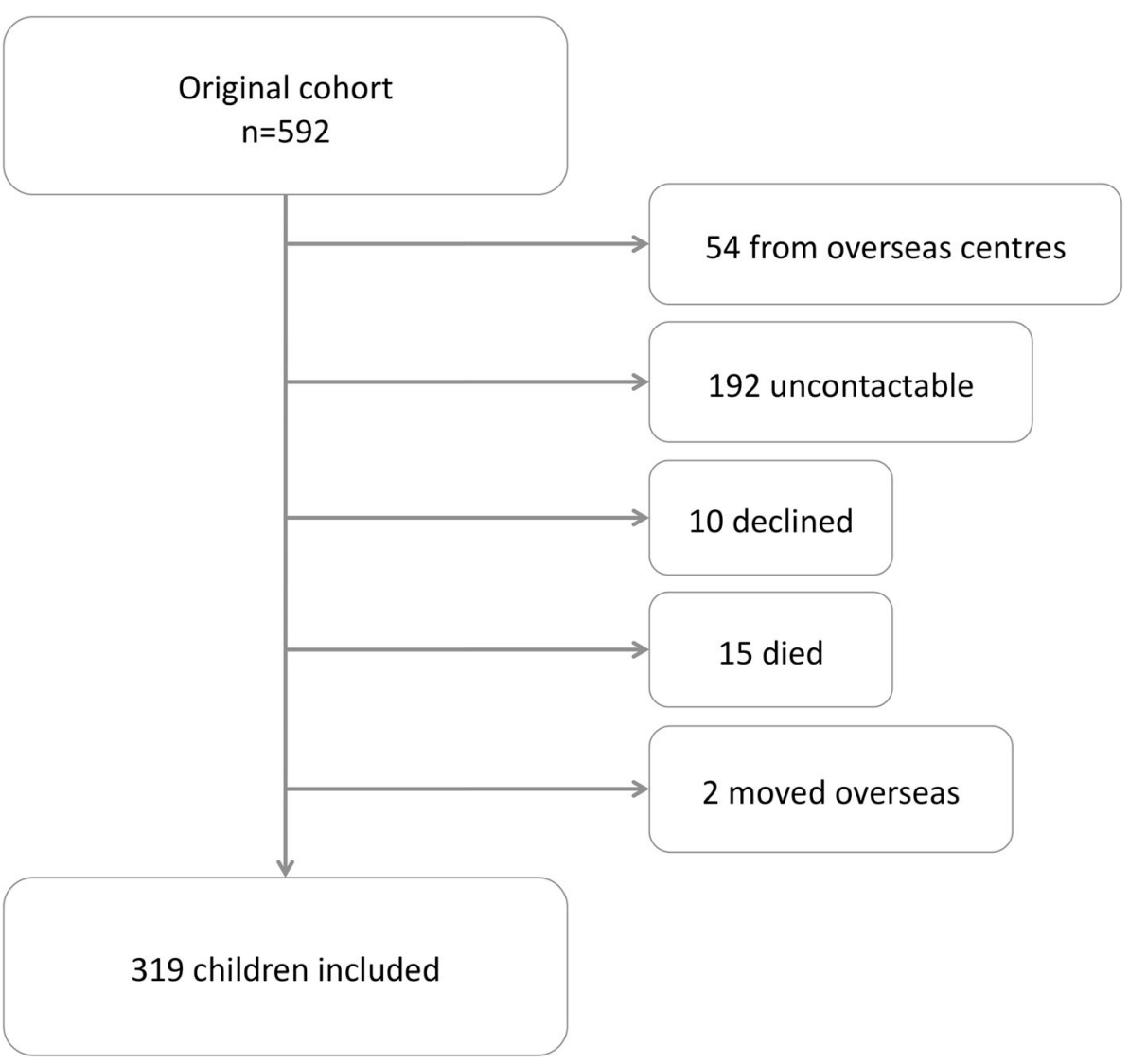

Fig. 1 Participant attrition in UKOS for follow-up measurements at 11-14 years of age

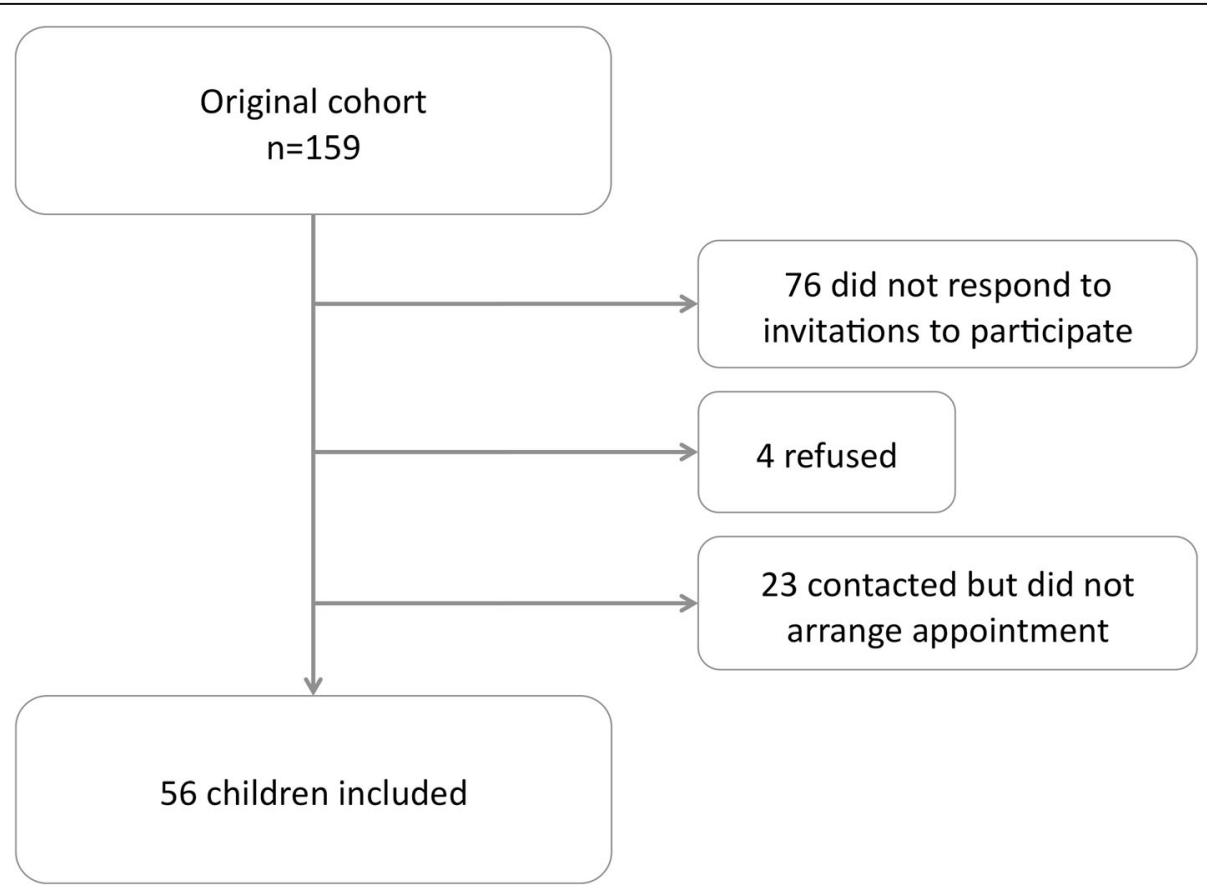

Fig. 2 Participant attrition at school age follow up in a study investigating the impact of early life viral lower respiratory tract infections in prematurely born infants 
Table 1 Characteristics of subjects who were and were not recruited for 11-14 year old follow up in the United Kingdom Oscillation Study

\begin{tabular}{llll}
\hline & Followed up $(n=319)$ & Not followed up $(n=204)$ & $p$ value \\
\hline Sex (M: F) & $162 / 319(51 \%)$ & $109 / 204(53 \%)$ & \\
Maternal ethnicity & & $149 / 203(73 \%)$ & $0.55^{*}$ \\
$\quad$ White & $285 / 318(90 \%)$ & $35 / 203(17 \%)$ & $19 / 203(9.3 \%)$ \\
Black & $21 / 318(6.6 \%)$ & $28.2(1.1$ to 70.0$)$ & $<0.001^{*}$ \\
Other & $12 / 318(3.8 \%)$ & $914(204)$ & $-0.41(-3.28$ to 2.17$)$ \\
Index of multiple deprivation (IMD) & $15.2(1.0$ to 68.1) & $26.7(1.39)$ & $0.001^{\text {b }}$ \\
Birth weight (g) & $895(209)$ & $45 / 204(22 \%)$ & $0.31^{\text {a }}$ \\
Birth weight (z score) & $-0.59(-3.45$ to 2.41$)$ & $203 / 204(99 \%)$ & $0.050^{\text {b }}$ \\
Gestational age (weeks) & $26.9(1.33)$ & $72 / 188(38 \%)$ & $0.35^{\text {a }}$ \\
Multiple birth & $76 / 319(24 \%)$ & $61 / 203(30 \%)$ & $0.64^{*}$ \\
Surfactant given & $310 / 319(97 \%)$ & $164 / 204(80 \%)$ & $0.097^{*}$ \\
Maternal smoking in pregnancy & $69 / 292(24 \%)$ & $44 / 204(22 \%)$ & $0.001^{*}$ \\
Postnatal steroids & $84 / 314(27 \%)$ & & $0.42^{*}$ \\
Oxygen dependency at 28 days & $262 / 319(82 \%)$ & $0.62^{*}$ \\
Oxygen dependency at hospital discharge & $71 / 315(23 \%)$ & $0.80^{*}$ \\
\hline
\end{tabular}

Data are shown as $\mathrm{n}(\%)$, median (interquartile range) or mean (SD)

indicates $p$ value generated from Chi squared analysis

afrom unpaired t test

${ }^{b}$ from Mann Whitney u test

\section{Discussion}

We have shown significantly different success rates in follow up of two studies of prematurely born infants. Comparison of participant characteristics between those who were and were not successfully followed up highlighted that there were no consistent predictive factors across the two studies which identified individuals at higher risk of loss to follow up. In the larger UKOS trial, non-white ethnicity, socioeconomic deprivation and maternal tobacco use were more prevalent in those who did not attend for

Table 2 Characteristics of subjects who were and were not recruited for school age follow up in the virus study

\begin{tabular}{|c|c|c|c|}
\hline & Followed up $(n=56)$ & Not followed up $(n=103)$ & $p$ value \\
\hline$\overline{\operatorname{Sex}(M: F)}$ & $28: 28$ & 59: 44 & $0.378^{*}$ \\
\hline \multicolumn{4}{|l|}{ Maternal ethnicity } \\
\hline White & $23 / 56(41 \%)$ & $32 / 103(31 \%)$ & Overall \\
\hline Black & $22 / 56(39 \%)$ & $54 / 103(52 \%)$ & \multirow[t]{2}{*}{$0.278^{c}$} \\
\hline Other & $11 / 56(20 \%)$ & 17/103 (17\%) & \\
\hline Index of multiple deprivation (decile) & $3(2-5)$ & $3(2-5)$ & $0.838^{\mathrm{b}}$ \\
\hline Birth weight $(g)$ & $1836(707)$ & $1937(571)$ & $0.036^{\mathrm{a}}$ \\
\hline Gestational age (weeks) & $33.86(30.71-34.86)$ & $33.71(31.71-35.29)$ & $0.435^{\mathrm{b}}$ \\
\hline Multiple birth & $22 / 56(39 \%)$ & 25/103 (24\%) & $0.048^{*}$ \\
\hline Surfactant given & $13 / 56(23 \%)$ & 20/103 (19\%) & $0.573^{*}$ \\
\hline Maternal smoking in pregnancy & $8 / 56(14 \%)$ & 17/103 (17\%) & $0.713^{*}$ \\
\hline Postnatal steroids & $2 / 56(4 \%)$ & $1 / 103(1 \%)$ & $0.250^{*}$ \\
\hline Oxygen dependency at 28 days & $2 / 56(4 \%)$ & 0/103 (0\%) & $0.054^{*}$ \\
\hline Oxygen dependency at hospital discharge & $11 / 56(20 \%)$ & $5 / 103(5 \%)$ & $0.003^{*}$ \\
\hline
\end{tabular}

Data are shown as $\mathrm{n}(\%)$, median (interquartile range) or mean (SD)

indicates $p$ value generated from Chi-squared analysis

afrom unpaired t test

brom Mann Whitney u test

'from Friedman's test 
follow up. In the virus study, lower birth weight, singleton birth and persistent oxygen requirement at hospital discharge were associated with greater follow up participation. In light of the lack of common factors associated with loss to follow up, we suggest that factors related to follow up study design may be more relevant.

We have demonstrated higher retention rates in a cohort with whom there had been regular contact to the follow-up stage [6]. Staff continuity and development of trust has been highlighted as helping to prevent attrition in a longitudinal study of lead-exposed children [11] and in a study of development in children of mothers with a history of substance misuse [12]. In both the studies we report the senior investigators remained the same, but junior researchers who undertook the measurements had changed from those in the original studies. The regular contact with the children and their families with cards and a newsletter in UKOS, we suggest may contribute to the differences in attrition between the two studies.

The factors associated with attrition differed between the two studies. The participants of UKOS were all born less than 29 weeks of gestational age and all had been ventilated from birth. It is then not surprising that the severity of their initial illness did not determine whether they consented to follow-up. Instead the significant risk factors for attrition were social factors, greater deprivation scores and intrauterine tobacco exposure. Previous studies have suggested that indicators of lower socioeconomic status are predictive of attrition in longitudinal studies commencing in infancy [13, 14]. Those data highlight individuals who may require more intense explanation regarding the importance of taking part in the follow-up. In addition, more were of non-white ethnicity which may suggest a need for more tailored support for those whose first language may not be English. In contrast, in the virus study determinants of initial illness severity were significantly related to attrition rate. Infants recruited into the virus study, although born prematurely, were significantly more mature than the UKOS cohort. It is likely those who had a higher birth weight, were not oxygen dependent at discharge or of a multiple birth had a very short time of routine clinical follow-up, which may have led to lower interest in engagement in the later research.

In the paediatric setting, various approaches have been suggested to optimise retention of study participants. Appointments must be flexible around family and work commitments [11, 15] and provision must be made for study participant's siblings, either by allowing siblings to attend appointments or, if this is not practicable, providing formal childcare $[11,12]$. Practical assistance in the form of arranging transport to attend studies (rather than simply reimbursing participants after attendance) and organising onward referrals to address any new incident health needs were further highlighted as being beneficial [11]. Both of our studies welcomed siblings to attend and offered appointments at weekends and during school holidays in addition to weekday appointments. Transport was arranged for all the UKOS participants as the majority lived outside London, whereas for the virus study reimbursement was given for travel, but not arranged, as participants lived within easy reach of the testing location. At the follow-up of both of our studies, the researchers assessed specific health needs and made onward referrals and recommendations as needed, but this was not explicitly advertised in the literature families received prior to recruitment.

The perception of the importance of the research may be a key determinant of choosing to participate [16]. In addition, in community-based clinical trials, it has been identified that participants' understanding of the study importance was a key determinant of retention [2]. The UKOS blog gave parents updates on publications arising from the study, thereby likely emphasising the success of the research programme.

Obtaining relatives' contact details as well as those of the participants or parents [17], making interim contact between study visits [18] and providing small financial incentives to update contact information $[19,20]$ have been suggested as effective methods to reduce attrition due to loss of contact. The annual birthday and seasonal greeting cards sent to the UKOS cohort asked parents to maintain up to date contact details. To undertake such activity carries a cost, thus it is important that additional funding for participant retention that extends beyond the end of the main funding source should be sought [19].

The use of study-specific (rather than institutional) logos may aid study retention $[19,21]$ by enforcing the identity of the study and may be a stronger reminder of previous participation than written descriptions. The UKOS newsletters regularly featured photographs of the study team, including senior investigators and previous members of the team as well as the study logo.

\section{Conclusions}

In conclusion, retention rates significantly differed between our two studies. Although differences were observed in the baseline characteristics of those lost to follow up versus retained, these factors were not common across the two studies. It seems plausible, therefore, that differences in follow up design explained the differing retention rates. We suggest, based on our experience and findings from the literature, that establishing and reinforcing the study's identity and purpose to participants, ongoing regular contact with participants beyond the completion of initial study and providing regular feedback on the study may improve retention at follow-up. 


\section{Abbreviations}

GA: Gestational age; LRTI: Lower respiratory tract infection; UKOS: United Kingdom Oscillation Study

\section{Acknowledgements}

We thank Mireia Alcazar-Paris and Theresa Wilson for their contribution to the follow up studies and Mrs. Deirdre Gibbons for secretarial assistance.

\section{Authors' contributions}

$A G$ and VMB designed the study, undertook the analysis of the results and wrote the initial draft of the manuscript. JLP was involved in the design of the original studies and JLP, SBD and SZ in their follow-up. All authors were involved in writing up the manuscript and approved the final version.

\section{Funding}

Dr. MacBean was supported by the KHP Challenge Fund. The research was supported by the National Institute for Health Research (NIHR) Biomedical Research Centre based at Guy's and St Thomas' NHS Foundation Trust and King's College London. The views expressed are those of the author(s) and not necessarily those of the NHS, the NIHR or the Department of Health.

\section{Availability of data and materials}

The datasets used and/or analysed during the current study are available from the corresponding author on reasonable request.

\section{Ethics approval and consent to participate}

The follow-up studies were approved by the South West London National Research Ethics Service Committee and the National Research Ethics Service Committee West Midlands - Coventry \& Warwickshire. Informed, written parental consent was given for all the children to take part in the follow-up studies.

\section{Consent for publication}

No Individual person's data is included.

\section{Competing interests}

The authors declare that they have no competing interests.

\section{Author details}

'Centre for Human Performance, Exercise and Rehabilitation, Brunel University London, London, UK. ${ }^{2}$ Oxford Vaccine Group, Department of Paediatrics, University of Oxford, Oxford, UK. ${ }^{3}$ Department of Paediatrics, University of Oxford, Oxford, UK. ${ }^{4}$ School of Population Health and Environmental Sciences, Faculty of Life Sciences \& Medicine, King's College London, London, UK. ${ }^{5} \mathrm{NIHR}$ Biomedical Research Centre at Guy's \& St Thomas' NHS Foundation Trust and King's College London, London, UK. ${ }^{6}$ Department of Women and Children's Health, School of Life Course Sciences, Faculty of Life Sciences \& Medicine, King's College London, London, UK. ${ }^{7}$ The Asthma UK Centre for Allergic Mechanisms of Asthma, King's College London, London, UK.

Received: 2 November 2018 Accepted: 30 August 2019 Published online: 06 September 2019

\section{References}

1. Zivanovic S, Peacock J, Alcazar-Paris M, Lo JW, Lunt A, Marlow N, et al. Late outcomes of a randomized trial of high-frequency oscillation in neonates. $\mathrm{N}$ Engl J Med. 2014;370:1121-30.

2. Davis JM, Parad RB, Michele T, Allred E, Price A, Rosenfeld W, North American Recombinant Human CuZnSOD Study Group, et al. Pulmonary outcome at 1 year corrected age in premature infants treated at birth with recombnant human CuZn superoxide dismutase. Pediatrics. 2003; 111:469-76.

3. Ambalavanan N, Tyson JE, Kennedy KA, Hansen NI, Vohr BR, Wright LL, et al. Vitamin A supplementation for extremelty low birth weight infants: outcome at 18 to 22 months. Pediatrics. 2005:115:e249-54.

4. Marcellus L. Are we missing anything? Pursuing research on attrition. Can J Nurse Res. 2004;36:82-98.

5. Johnson AH, Peacock JL, Greenough A, Marlow N, Limb ES, Marston L, et al. High-frequency oscillatory ventilation for the prevention of chronic lung disease of prematurity. N Engl J Med. 2002;347:633-42.
6. Thomas MR, Rafferty GF, Limb ES, Peacock JL, Calvert SA, Marlow N, et al. Pulmonary function at follow-up of very preterm infants from the United Kingdom oscillation study. Am J Respir Crit Care Med. 2004;169:868-72.

7. Marlow N, Greenough A, Peacock JL, Marston L, Limb ES, Johnson AH, et al. Randomised trial of high frequency oscillatory ventilation or conventional ventilation in babies of gestational age 28 weeks or less: respiratory and neurological outcomes at 2 years. Arch Dis Child Fetal Neonatal Ed. 2006;91:F320-6.

8. Drysdale SB, Lo J, Prendergast M, et al. Lung function of preterm infants before and after viral infections. Eur J Pediar. 2014;173:1497-504.

9. Drysdale SB, Alcazar M, Wilson T, Smith M, Zuckerman M, Hodemaekers, et al. Functional and genetic predisposition to rhinovirus lower respiratory tract infections in prematurely born infants. Eur J Pediatr. 2016;175:1943-9.

10. MacBean V, Drysdale S, Yarzi MN, Peacock JL, Rafferty GF, Greenough A. Respiratory viral infections in infancy and school age respiratory outcomes and healthcare costs. Pediatr Pulmonol. 2018;53:342-8.

11. Adubato S, Alper R, Heenehan M, Rodriquez-Mayor L, Elsafly M. Successful ways to increase retention in a longitudinal study of lead-exposed children. Health Soc Work. 2003;28:312-5.

12. Graziotti AL, Hammond J, Messinger DS, Bann CM, Miller-Loncar C, Twomey $J$, et al. Maintaining participation and momentum in longitudinal research involving high-risk families. J Nurs Scholarsh. 2012:44:120-6.

13. Aylward GP, Hatcher RP, Stripp B, Gustafson NF, Leavitt LA. Who goes and who stays: subject loss in a multicenter, longitudinal follow-up study. J Dev Behav Pediatr. 1985;6:3-8.

14. Zook PM, Jordan C, Adams B, Visness CM, Walter M, Pollenz K, et al. Retention strategies and predictors of attrition in an urban pediatric asthma study. Clin Trials. 2010;7:400-10.

15. Gul RB, Ali PA. Clinical trials: the challenge of recruitment and retention of participants. J Clin Nurs. 2010;19:227-33.

16. Newburg SM, Holland AE, Pearce LA. Motivation of subjects to participate in a research trial. Appl Nurs Res. 1992:5:89-93.

17. Rosal MC, White MJ, Borg A, Scavron J, Candib L, Ockene I, et al. Translational research at community health centers: challenges and successes in recruiting and retaining low income Latino patients with type 2 diabetes into a randomized clinical trial. Diabetes Educ. 2010;36:733-49.

18. Lyons KS, Carter JH, Carter EH, Rush KN, Stewart BJ, Archbold PG. Locating and retaining research participants for follow-up studies. Res Nurs Health. 2004;27:63-8.

19. Aitken L, Gallagher R, Madronio C. Principles of recruitment and retention in clinical trials. Int J Nurs Pract. 2003;9:338-46.

20. Chang M, Brown R, Nitzke S. Participant recruitment and retention in a pilot program to prevent weight gain in low-income overweight and obese mothers. BMC Public Health. 2009:9:424.

21. Nicholson L, Schwirian PM, Klein EG, Skybo T, Murray-Johnson L, Eneli I, et al. Recruitment and retention strategies in longitudinal clinical studies with low-income populations. Contemp Clin Trials. 2011;32:353-62.

\section{Publisher's Note}

Springer Nature remains neutral with regard to jurisdictional claims in published maps and institutional affiliations.
Ready to submit your research? Choose BMC and benefit from:

- fast, convenient online submission

- thorough peer review by experienced researchers in your field

- rapid publication on acceptance

- support for research data, including large and complex data types

- gold Open Access which fosters wider collaboration and increased citations

- maximum visibility for your research: over $100 \mathrm{M}$ website views per year

At $\mathrm{BMC}$, research is always in progress.

Learn more biomedcentral.com/submissions 